\title{
La mediación escolar rural y su potencial en el fomento de la mediación policial
}

\section{Rural school mediation and its potential in promoting police mediation}

\author{
CD. Sara Yesenia Blanco Grimaldo² \\ CD. Angélica María Contreras Nuncira ${ }^{3}$ \\ CD. Heidy Tatiana Contreras Bautista ${ }^{4}$
}

Ernesto Fajardo Pascagaza. ${ }^{5}$

Nubia Edith Céspedes Prieto ${ }^{6}$

$1 \quad$ Artículo producto de la investigación realizada en desarrollo de la Especialización en servicio de Policía en torno a la relación entre mediación escolar rural y mediación policial.

$2 \quad$ Cadete de la escuela de cadetes de Policía "General Francisco de Paula Santander", Enfermera Profesional, E-mal: sara.blanco@correo.policia.gov.co.Orcid: https://orcid.org/0000-0003-3113-6640

$3 \quad$ Cadete de la escuela de cadetes de Policía "General Francisco de Paula Santander", Abogado,

E-mal: am.contrer00002@correo.policia.gov.co Orcid: https://orcid.org/0000-0003-4608-5575

$4 \quad$ Cadete de la escuela de cadetes de Policía "General Francisco de Paula Santander", Abogado,

E-mal: heidy.contreras@correo.policia.gov.co Orcid: https://orcid.org/0000-0002-4178-1814

5 Doctorando en Educación, Doctorando en Filosofía, Magíster en Filosofía y Magíster en Educación. Docente del Departamento de Humanidades y Formación Integral de la USTA. Integrante del Grupo de Investigación ALETHEIA Categorizado Colciencias en A1. Investigador Categorizado por Colciencias como Investigador Asociado.

Correo electrónico: ernesto- fajardo@usantotomas.edu.co Orcid: https://orcid.org/0000-0003-1168-9512

6 Doctora en Ciencias, Magister en Ciencias Químicas, Licenciada en Química y Biología, Ingeniera Ambiental. Docente de la ECSAN. Integrante del Grupo de Investigación ECSAN Categorizado por Colciencias en C. Investigadora Categorizada por Colciencias como Investigadora Asociada. Correo electrónico: necespedesp@unal.edu.co Orcid: https://orcid.org/0000-0001-6334-989X 


\section{RESUMEN}

Con el objetivo de describir el estado actual de la mediación escolar en el sector rural para utilizarlo en el servicio de Policía como herramienta que potencialice el uso de la mediación Policial en las comunidades rurales se desarrolló una investigación documental de carácter cualitativo que permitió establecer una contextualización de la ruralidad, la escolaridad en dicha zona, los conflictos educativos que se presentan, la mediación por parte de pares para revolverlos y su relación con la mediación policial.

Valga decir que el principal hallazgo es la poca existencia de experiencias significativas que documenten este aspecto y por consiguiente no existe fundamentos para hablar de una mediación escolar exitosa que ofrezca insumos para potenciar la mediación policial, por lo tanto luego de la discusión propia que ofrecieron los resultados y ante la imposibilidad de pensar en aportes de la mediación escolar a la mediación policial cuando la primera no existe sino teóricamente; se optó invertir la propuesta para que desde la institucionalidad de la Policía Nacional se proyecte la mediación escolar rural y, a un futuro, esta sea el fundamento de la mediación policial rural.

Palabras claves: ruralidad, mediación escolar, mediación policial.

\section{SUMMARY}

In order to describe the current state of school mediation in the rural sector to use it in the Police service as a tool to enhance the use of Police mediation in rural communities, a qualitative documentary investigation was carried out that allowed establishing a contextualization rurality, schooling in that area, educational conflicts that arise, mediation by peers to stir them up and their relationship with police mediation.

It is worth saying that the main finding is the little existence of significant experiences that document this aspect and therefore there is no basis to speak of a successful school mediation that offers inputs to enhance police mediation, therefore after the own discussion offered by the results and in the face of the impossibility of thinking about contributions from school mediation to police mediation when the former only exists theoretically; it was decided to invest the proposal so that the rural school mediation is projected from the institutional framework of the National Police and, in the future, this is the foundation of rural police mediation.

Key words: rurality, school mediation, police mediation

\section{INTRODUCCIÓN}

Con el objetivo de describir el estado actual de la mediación escolar en el sector rural para utilizarlo en el servicio de Policía como herramienta que potencialice el uso de la mediación Policial en las comunidades rurales se diseña el presente documento en el cual se construye un sistema paradigmático en el que se busca contextualizar tanto espacial, temporal y conceptualmente el objeto de investigación, para así poderla abordar de manera general.

Luego de un trabajo de recolección de información y de selección de literatura especializada en el tema se ubica el contexto en el que se 
desarrolla la investigación. En primer lugar, grosso modo, desde el aspecto histórico- social, se estableció una realidad de la población rural, enquistada en el abandono, olvido, inequidad y violencia, con un componente que agrava dicha situación: la negación de oportunidades como consecuencia del difícil acceso y permanencia en el sistema escolar; seguidamente se pasa a revisar el modelo de Escuela Nueva que funciona hace más de cinco décadas y que permite, con las dificultades propias del entorno, cierta posibilidad de educación al campesinado colombiano, para luego pasar a conceptualizar lo referente al matoneo escolar, conocido como Bullying; posteriormente se revisa el concepto y la categorización de la mediación escolar como alternativa para la resolución de conflictos y portavoz de alertas tempranas que disminuyan el riesgo de desencadenar hechos de vulnerabilidad de derechos a menores; terminando con el papel de la mediación policial en la zona rural el cual se debe fundamentar en los lazos de confianza que se construyan a partir de la escuela rural para su contribución institucional en la construcción de una paz firmemente consolidada.

\section{DESARROLLO}

\section{Lo Rural y la Violencia en Colombia}

El concepto de rural es lo opuesto a lo urbano y demarca los sectores donde se desarrollan actividades tales como la agricultura, la agropecuaria y la ganadería, entre otras. Entendido así lo rural se puede pasar a describir su realidad, lo cual no es tarea de esta investigación, pero si se requiere de su observación para poder abordar el problema con conocimiento de causa.

En Colombia, referirse a lo rural es sinónimo de inequidad y paradójicamente se relaciona de manera muy estrecha con pobreza. Un informe del Centro Noruego para Resolución de conflictos afirma que la pobreza, la marginalidad, la ausencia de servicios públicos básicos, la carencia de educación de calidad y oportuna, son los protagonistas en las regiones rurales (González, 2016) y citando el último censo nacional, donde declara que el $45,6 \%$ de las personas residentesenelárearural dispersaviven en condiciones de "pobreza multidimensional" entendiéndose a esta población como las personas que sufren de escasez en la vida en general como en las dimensiones de educación, salud, trabajo, seguridad social, vivienda (...) y no solo como la falta ingresos para cubrir las necesidades, tal como lo define el Programa de las Naciones Unidas para el Desarrollo (PNUD). El mismo censo indica que este porcentaje de pobreza aumenta a $63.8 \%$ cuando se suma condiciones de pobreza de grupos étnicos y poblaciones desplazadas por la violencia del conflicto armado (González, 2016). Así mismo, declara que estas zonas son las más afectadas a través de la historia por la presencia de grupos armados y la violencia; al citar un estudio del año 2012, fundamenta que "el $57 \%$ de los niños y jóvenes reclutados para la inserción a los grupos armados al margen de la ley, son procedentes de familias de clase muy baja" (González, 2016). Ciertamente basta repensar la situación para deducir que la falta de educación y de oportunidades laborales aunada con el estado de pobreza social de la zona rural colombiana, fue un perfecto caldo de cultivo para perpetuar el conflicto armado durante más de cincuenta años en este país.

El conflicto armado focalizado en las zonas rurales del país, acompañado del olvido estatal, se convierte en factores determinantes para que se genere una situación educativa deplorable, representada en la falta de acceso a su sistema, la deserción escolar y su dudosa calidad académica. El estudio también evidencia cifras alarmantes del estado de la educación rural, donde más del $20 \%$ de los niños y adolescentes campesinos en edades entre 5 y 16 años no asiste a la escuela, porcentaje que se incrementa 
a un $73,7 \%$ entre los jóvenes de 17 y 24 años de edad. A su vez, la mitad (50\%) de los niños, adolescentes y jóvenes rurales no culminan sus estudios de primaria o el quinto grado escolar (González, 2016).

Además Fajardo (2018) habla sobre la inequidad en el aprendizaje entre escuelas, mencionando algunos factores influyentes como: "la inadecuada infraestructura, poca cualificación del personal docente, el difícil acceso, la pobreza, la migración por violencia, las dificultades de cobertura y falta de calidad en la educación, la falta de política en gasto público de educación (...)" todo ello contribuye al déficit en educación rural en el país.

En la actualidad, cuando el tema del postconflicto es una realidad que pretende la unión integral de la nación, es necesario plantear una perspectiva de la educación de los niños y adolescentes del sector rural, que hoy hacen parte del personal desvinculado y desmovilizado de los grupos subversivos, que se avistan a recorrer las rutas de la reincorporación social y por consiguiente una futura integración al sistema educativo, permitiendo suponer que sus niveles de formación escolar son relativamente bajos. Según datos de la agencia colombiana para la reintegración (ACR), solo el $28 \%$ de la población desmovilizada han culminado su etapa de bachillerato figurando menos de la tercera parte de dicha población; todo esto desde una visión proactiva, se puede subsanar al entender que la educación será la herramienta fundamental para escribir un nuevo capítulo en la historia de Colombia y dar punto final a las perpetuadas situaciones de violencia y sanar las heridas de la guerra.

\section{EDUCACIÓN RURAL COLOMBIANA}

Al abordarse el tema de la Educación rural colombiana, el informe del Centro Noruego para la Resolución de Conflictos (2016), tiene el convencimiento de que "El Plan Especial de Educación Rural" de los acuerdos de Paz es fundamental para poner en marcha dichos tratados, su omisión sería funesto y no ayudaría en nada a restablecer el pacto social. El Estado no puede seguir dando trato de cenicienta a la educación rural, esto se desprende al observar que en el año 2014 la inversión estatal realizada en educación fue del $4,6 \%$ del PIB. Siendo de este leve porcentaje, el $0,5 \%$ destinado a la educación rural. Siguiendo en el contexto, estudios declaran que seguir las recomendaciones de la Misión para la Transformación del Campo (MTC) en lo pertinente a la educación rural, sería imperativo una inversión del $1,2 \%$ del PIB a lo largo de quince años; traduciéndose en un incremento anual del $0,7 \%$ del PIB (González, 2016).

El panorama de la educación rural es sombrío. El Estado Colombiano está en deuda con los menores del país, pero especialmente con quienes residen en zona rural puesto que se les ha negado o cercenado cualquier oportunidad, siendo la educación el primer escalón para crear y/o alcanzar esas oportunidades. Colombia debe asumir el reto de reivindicarse con la educación rural, comprometiéndose institucional y políticamente para que se proyecte la adecuada inversión de recursos de toda índole en la educación rural, logrando hacerla generadora de oportunidades y mediadora de paz.

Es preciso aclarar que el sistema educativo rural colombiano tiene características muy individuales y difiere fundamentalmente de los modelos de educación formal urbana. La educación Rural responde a un modelo conocido como "Escuela Nueva", la cual no es tan nueva pues data de hace más de cincuenta años y su objetivo fue el de garantizar la educación a las poblaciones rurales, adaptándola a las características del contexto en cuanto a la productividad del campo.

Los calendarios flexibles de este modelo se deben al bajo número de estudiantes que se presentan, los cuales en los diversos grados 
son acompañados por un solo docente, presentándose la figura de mono-docente rural. El Modelo parte hacia el año 1961, con la financiación de la UNESCO, logrando gran éxito que la llevo, siete años después, a extenderse a todo el país por el Ministerio de Educación Nacional (Arboleda, 2018)

Arboleda (2018), considera que este modelo se caracteriza por estar basado en el aprendizaje activo, brinda una promoción flexible, establece una clara relación escuela -comunidad, fomenta el aprendizaje cooperativo centrado en el alumno, y ofrece estrategias a nivel curricular, comunitarias, de capacitación, seguimiento y evaluación.

Al respecto el Ministerio de Educación Nacional ofrece una amplia definición donde conceptualiza las diversas e importantes características del modelo, para lo cual lo define así:

La Escuela Nueva es una opción educativa formal, estructurada; con bases conceptuales tan bien definidas y relacionadas que puede considerarse como una alternativa pedagógica pertinente para ofrecer la primaria completa a favor del mejoramiento cualitativo de la formación humana que se brinda a los niños y las niñas en las zonas rurales del país. Acoge y ejecuta los principios y fundamentos de las pedagogías activas y atiende la realidad de la población rural de Colombia. (MEN 2011, p.8).

El impacto y aceptación del Modelo educativo "Escuela Nueva" ha sido tal que Arboleda (2018) Indica que según datos del Sistema Integrado de Matrícula (SIMAT, 2010). "el Plan de Escuela Nueva (PEN) ha tenido tanto éxito que para el año 2010 en Colombia existen cerca de 25.313 establecimientos educativos que implementan esta metodología, con un registro de matrícula de 812.580 alumnos en todo el país." pero a manera de alerta, agrega que el papel excesivamente directivo o paternalista del maestro, al igual como la formalidad y los rituales -tan caros a la cultura escolar- terminan en muchas ocasiones, vaciando de contenido al organismo y al proceso. Por lo cual, vale decir que el proceso dinamizador y la efectividad del modelo depende en gran parte de la formación, trabajo y compromiso del educador y de la relación con las familias de la comunidad educativa.

\section{CONFLICTO ESCOLAR, VIOLENCIA ESCOLAR O BULLYING}

El término Bullying es una palabra de origen inglés y no aparece en el Diccionario de la Real Academia de la lengua, etimológicamente se compone por la fracción "bully" que significa "matón" o "peleón" y el "ing" al final indica una acción o el resultado de ella; también es conocido como "acoso escolar" o "hostigamiento escolar", asociado a la violencia escolar, o a la falta de convivencia escolar, comúnmente conocido como matoneo escolar. Éste no sólo es un anglicanismo más, es una problemática que debe ser enfrentada para reducirla a su mínima expresión y por ende reducir radicalmente sus nefastos efectos en al campo escolar.

El Observatorio de Derechos Humanos y Paz de UNICIENCIA. (2019) hace una interesante recopilación de diversas definiciones que la literatura presenta sobre el bullying. Cita a Sanmartín-Esplugues, quien lo define como "una especie de tortura, metódica y sistemática, en la que el agresor somete a la víctima, a menudo con el silencio, la indiferencia o la complicidad de otros compañeros" (2007); igualmente cita al Fondo de las Naciones Unidas para la Infancia UNICEF, que lo conceptúa como "una forma de discriminación de unos estudiantes hacia otro(s) por sus diferencias en características o forma de vida tales como: orientación sexual, nacionalidad, sexo, situación migratoria, etnia, identidad de género, condición socioeconómica, condición de salud, discapacidad, creencias, opiniones, prácticas basadas en estigmas sociales, embarazo, entre otras" (UNICEF, 2012). 
De la misma manera es citada la Asociación de Psicólogos Americanos (APA), que define este fenómeno como "una forma de comportamiento agresivo en la cual alguien causa lesiones o inconformidad a otra persona intencional y repetidamente. El bullying puede tomar forma de contacto físico, palabras o acciones sutiles" (2004).

Revisando las anteriores definiciones se puede establecer algunos factores inherentes a la problemática que son observables y por lo tanto predecibles y prevenibles; entre esos factores está la intencionalidad y sistematicidad del acto, las lesiones y/o dolor causado, la complicidad, el silencio y los elementos discriminatorios.

Precisando el concepto de bullying en el ámbito escolar colombiano es pertinente acudir la normatividad que regula lo referente a esta problemática. El congreso de la República expidió la Ley 1620 de 2013, por la cual se crea el Sistema Nacional de Convivencia Escolar y Formación para el Ejercicio de los Derechos Humanos, la Educación para la Sexualidad y la Prevención y Mitigación de la Violencia Escolar. Dicha ley en su artículo segundo define el bullying y el Ciberbullying o ciberacoso escolar en los siguientes términos:

- Acoso escolar o bullying: Conducta negativa, intencional metódica y sistemática de agresión, intimidación, humillación, difamación, coacción, aislamiento deliberado, amenaza o incitación a la violencia o cualquier forma de maltrato psicológico, verbal, físico o por medios electrónicos (ciber acoso) contra un niño o adolescente, por parte de uno o varios estudiantes con quienes mantiene una relación de poder asimétrica, que se presenta de forma reiterada o a lo largo de un tiempo determinado.

También puede ocurrir por parte de docentes contra estudiantes, o por parte de estudiantes contra docentes, ante la indiferencia o complicidad de su entorno. El acoso escolar tiene consecuencias sobre la salud, el bienestar emocional y el rendimiento escolar de los estudiantes y sobre el ambiente de aprendizaje y el clima escolar del establecimiento educativo.

- Ciber bullying o ciber acoso escolar: Forma de intimidación con uso deliberado de tecnologías de información (internet, redes sociales virtuales, videojuegos online y telefonía móvil) para ejercer maltrato psicológico y continuado." (Ley 1620, 2013)

Conceptualizado el bullying se entiende como un fenómeno de carácter social que afecta el proyecto de vida de cada uno de los infantes y adolescentes víctimas de esta situación, se procede a revisar la mediación escolar como alternativa para mejorar ese estado de vulneración en los colegios.

Fajardo y parada (2018) referencian en su artículo sobre formación ciudadana a Hoyos (2017, p. 50) donde expone: "la ciudadanía es el reconocimiento del otro como Diferente" de este modo, se fundamenta la realidad social como una actitud de pensamiento incluyente que cada persona debe asumir.

Complementando con el pensamiento de Fajardo (2015) que expresa: "los niños son los sujetos centro de atención de la formación escolar, porque al fin y al cabo en un tiempo van a ser los ciudadanos que la sociedad necesita y que deberán caracterizarse por ser críticos, argumentativos y propositivos en contextos de pensamiento y de praxis social" argumentando la obligación de enseñar una materia curricular de convivencia ciudadana.

A través del proceso de mediación en las escuelas se debe generar impacto externo e interno contextualizando en casos de matoneo e intolerancia, al brindar una solución puntual al conflicto (Impacto externo) y al momento de mostrar otra perspectiva de posibles acuerdos, asumiendo el menor, la responsabilidad 
que contrae, realizar un análisis reflexivo a conciencia de su accionar, que a la final refuerce su identidad como miembro de una comunidad, de este modo revelar la mejor versión de su valor humano (Impacto Interno). Para dar fuerza a la tesis de la importancia de la educación como base generadora de sociedad se puede plantear lo siguiente:

Al permitir la escuela la toma de libres decisiones, enseña a tener autonomía.

Al tener autonomía, se refuerza la identidad de responsabilidad.

Al asumir la responsabilidad como elemento de vida, se involucra el funcionamiento del pensamiento crítico.

$\mathrm{Y}$ un pensamiento crítico, implica una participación activa pluralista para lograr intereses individuales y colectivos; Todo esto junto a una correcta autorregulación personal, realza los lineamientos éticos de los ahora estudiantes y siempre personas.

\section{LA MEDIACIÓN ESCOLAR}

La mediación escolar es concebida como alternativa para superar el estado de vulneración flagrante de los más mínimos derechos de los menores en la escuela.

El tema de mediación escolar, aunque suena novedoso, ha tenido una amplia trayectoria; de hecho, la literatura al respecto es muy amplia y presenta disímiles enfoques; sin embargo, es importante definir una apreciación conceptual que sirva de base y sea independiente pero coherente con los diversos enfoques que se den al respecto.

Pulido, et al. (2013) en su artículo titulado "Orígenes de los programas de mediación escolar: diferentes enfoques que influyen en esta práctica restaurativa" hace un recorrido en la historia de la mediación y la define de la siguiente manera:

La mediación es una técnica que busca ayudar a que personas enfrentadas puedan entender su conflicto de una manera más constructiva, intentando llegar a medios colaborativos de solución. Para ello, se basa en la ayuda de un tercero, denominado mediador (a), su función es facilitar el análisis de lo sucedido, así como de las posibles soluciones al futuro. La mediación es un proceso estructurado, con unos pasos a seguir y unas herramientas conocidos y manejados por el mediador. Se debe caracterizar por su neutralidad e imparcialidad, ya que su función es la de asistir a las partes enfrentadas a que ellas mismas entiendan la situación y cómo quieren solucionarlo." (Pulido, et al., 2013)

El mismo autor en otro de sus trabajos de investigación, define una serie de características propias del proceso de mediación, las cuales se pueden sintetizar así: se pretende un acuerdo, existe voluntad de las partes, se requiere de la intervención de un tercero, es un proceso alternativo a la confrontación ganador-perdedor, y busca la transformación positiva del conflicto.

Martín-Seoane, (2008), citado por Pulido, et al. (2013) Hace una aclaración sobre el proceso de mediación en el panorama escolar, indicando que este debe estar antecedido de la preocupación por propender por una educación integral que desarrolle competencias ciudadanas, con inclusión de la comunidad educativa en formación como mediadores e incluso destacando el valor de la efectividad de la mediación entre pares entendida esta como el acercamiento entre iguales.

En este aspecto de la mediación es muy importante el compromiso, la pertinencia, la apropiación y el convencimiento que el mediador debe tener al asumir su rol como un ejercicio de convivencia social, como parte de sí mismo, como desarrollo de su proyecto de 
vida. En ese aspecto Soler-Barón en su artículo titulado "La mediación de conflictos entre pares y la formación de competencias ciudadanas en la escuela" establece de manera puntual que:

"Las experiencias de mediación pueden llegar a constituir un mecanismo aislado, o promover una transformación de la convivencia escolar. Por esto, es necesario comprender que la mediación entre pares va más allá de un conjunto de procedimientos para resolver los conflictos, sino que también desprende una filosofía de la convivencia. Para asegurar ese alcance debe garantizarse que los mediadores, y los docentes que los apoyan, personifiquen una nueva actitud frente a las relaciones sociales que tienen lugar en la escuela, y activen esa actitud como símbolo de la cultura escolar en los establecimientos educativos." (Soler-Barón, 2011).

Al asumir la mediación escolar, como mecanismo alternativo para la resolución de conflictos en la escuela rural, con proyección social y comunitaria, se puede hacer un trabajo prospectivo sobre la incidencia de este comportamiento en la convivencia social para utilizarlo, en el logro del objetivo propuesto en el presente trabajo, en el servicio de Policía como herramienta que potencialice el uso de la mediación Policial en las comunidades rurales.

En ese orden de ideas vale revisar que el postconflicto en Colombia, exigirá de la Institución Policial un compromiso transformador que requiere de un ejercicio formativo de su personal. De hecho, Céspedes-Prieto (2018) citando a Jaramillo (2015) retoma las recomendaciones que éste último hace a la institución, en las que indica que la Policía Nacional "debe ser una de las primeras afectadas en su transformación, dado que el mantenimiento tanto de sus miembros como de las políticas militares, son generadoras de confianza entre la población."

No es un secreto que los acuerdos de paz requieren de una institución comprometida en la formación permanente de sus integrantes con la implementación de políticas educativas reconciliadoras que propendan por el encuentro entre la ciudadanía y la institución fundado en principios de confianza mutua.

Con respecto a su compromiso con el sector rural, Céspedes-Prieto (2018), citando a (PONAL, 2010) y (Policía Nacional, 2015, p. 19), expresa que "la Policía Nacional ha expuesto la existencia de la obligación de vigorizar las facultades operativas en las zonas rurales y debido a esto, debe adaptar los programas académicos actuales haciendo hincapié en la seguridad rural" y agrega que debe haber priorización por este sector ya que históricamente es donde el conflicto se ha perpetuado y sus consecuencias han sido desoladoras. Por consiguiente, "debe ser primordial la seguridad rural y para que esto sea se requieren personal policial capacitado en el trabajo con la comunidad del campo, donde la presencia policial debe respaldarse." $Y$ éste trabajo sólo se logra mientras sea una realidad el acompañamiento y la confianza mutua con la población rural, para lo cual es fundamental que, desde la escuela, en el ejercicio de la mediación escolar, se fundamente la mediación policial ciudadana.

\section{MEDIACIÓN POLICIAL}

Para hablar de la mediación policial es importante retomar un trabajo de investigación titulado "Rol mediador de la policía nacional de Colombia en el posconflicto: Un estudio del discurso de expertos con AEDT" (Ramírez y Céspedes, 2016) que establece los "nuevos roles" que deberán ser asumidos por la Policía Nacional de Colombia para el periodo del posconflicto, como plan estratégico de reconciliación de los diferentes grupos sociales y los actores del conflicto.

La investigación citada establece que los nuevos ejes estratégicos de la Policía Nacional de Colombia son la seguridad ciudadana 
y convivencia. De hecho, citando a Bello (2014) indica que "La Policía Nacional, al ser un cuerpo civil armado, es la institución con responsabilidades y funciones específicas para brindar las garantías que den acceso a la práctica de la convivencia armónica entre las ciudadanías".

Siendo pues los ejes temáticos institucionales la Seguridad ciudadana y la convivencia es importante aclarar que esta se debe concebir "como el proceso de vivir con otros, en armonía y con el respeto de los derechos y obligaciones de los demás seres humanos" que "Desde la ciencia de policía, la convivencia se concibe como su fin fundamental, estructurado a partir de cuatro categorías: seguridad, moralidad, tranquilidad y ecología. Estos elementos son interdependientes y recíprocos, al tiempo que definen un concepto de convivencia ampliado, por cuanto no involucra solamente el compartir un territorio, sino el hacerlo en un ambiente equilibrado y sustentable" (Suárez, 2009a citado por Ramírez y Céspedes, 2016).

Es importante que al abordar este tema de la "Mediación Policial" se entienda la naturaleza civil y sus funciones relacionadas con el tema de la convivencia de la Policía Nacional ; además hay que considerar que una de su principales actividades son los procesos de mediación y resolución de conflictos, lo cual no se aborda solo como un problema de seguridad ciudadana sino que es importante el trabajo serio y proactivo tanto con la víctima como con el victimario, en busca de la "reinserción social" haciendo que el conflicto y sus actores asuman un ejercicio de transformación.

El estudio citado establece que la institución policial está en la tarea de incluir dentro de su formación módulos de Mediación Policial, no sólo para conocerlos sino para que se adquieran habilidades específicas que faciliten las actividades con la comunidad, indicando que "Es necesario que estos procesos de mediación tengan la validez y el soporte legal que les den legitimidad. Estos módulos deben fundamentarse no solo en elementos teóricos, sino incluir actividades prácticas, juegos de roles, que permitan a los policías anticipar y conocer las posibles situaciones que enfrentarán" (Bello, 2014 citado por Ramírez y Céspedes, 2016).

Es entones la "mediación policial" una necesidad manifiesta en el marco del post conflicto, de hecho desde la perspectiva de Hartzel (1999) citado por citado por Ramírez y Céspedes, (2016); "la estabilidad de los acuerdos de paz se fundamentan en las garantías que puedan aportar las instituciones, y el reconocimiento en la misión policial de garantizar a la ciudadanía seguridad y convivencia a través de la formación de talento humano, el desarrollo de la investigación etnográfica aplicada a nuevas estrategias de seguridad, y especialmente la formación de líderes que contribuyan al fortalecimiento de la convivencia ciudadana en espacios de interacción generados dentro del marco del posconflicto."

\section{MÉTODOS}

Este proyecto tomará como tipo de investigación la denominada documental de carácter expositivo, con enfoque cualitativo. Para lo cual es necesario definirla por apartes.

La investigación documental o bibliográfica se define "como una serie de métodos y técnicas de búsqueda, procesamiento y almacenamiento de la información contenida en los documentos, primeramente, y la presentación sistemática, coherente y suficientemente argumentada de nueva información en un documento científico, en segunda instancia. De este modo, no debe entenderse ni agotarse la investigación documental como la simple búsqueda de documentos respecto a un tema específico." Tamara (1988). Entendido de esta manera que el objeto de estudio por su complejidad y 
amplitud se debe abordar desde lo bibliográfico, lo documental.

Igualmente se debe entender que este trabajo bibliográfico es de carácter expositivo ya que "no busca objetar un tema sino recrear el contexto teórico de la investigación. Para ello se vale de fuentes confiables, y de la selección y el análisis del material en cuestión" (Matos 2019). Igualmente se determinó que su enfoque es de carácter cualitativo puesto que "no solo se limita a la revisión de documentos, sino que centra su interés en el presente o pasado cercano. Conocer un fenómeno social y cultural a partir de textos escritos. Los diseños de investigación cualitativa de todo género suelen utilizar este tipo de datos para completar la visión del escenario social del fenómeno de estudio, aunque es cierto la investigación documental puede ser por sí misma un diseño". (UJA. 2018)."

Debido a que los datos y la información recolectada, evaluada y tratada en el presente proyecto son aportes de diferentes autores y fuentes que se categorizan como datos secundarios, se considera oportuna la realización de un aporte propio a través de la obtención de datos Primarios recolectados en campo por las autoras, referente al estado actual de la metodología de mediación escolar en zonas rurales del departamento de Norte de Santander, puntualmente en veredas del municipio del Zulia.

\section{RESULTADOS}

Luego de hacer un trabajo documental se pudo establecer los siguientes resultados:

Es escasa la literatura sobre aplicación de mediación escolar en Colombia. Las pocas pruebas pilotos no pueden ser tomadas como referencia de la ruralidad porque este concepto es muy amplio y heterogéneo.

Se establece que la mediación escolar es una eficaz estrategia de socialización del menor, quien fácilmente adopta el diálogo y la conciliación como elementos para solucionar conflictos

Existen suficientes fundamentos de carácter psicológico, social y pedagógico para asumir la mediación escolar herramienta de convivencia.

Está demostrado que el bullying es un grave problema que afecta la formación integral del menor y es factor potencial para recrear escenarios mayormente graves.

Existen suficientes directrices legales e institucionales para contrarrestar la violencia escolar.

La Mediación puede observarse como una herramienta en la que existen serios vacíos en su funcionamiento, debido a la falta de formación, preparación y adecuación para que éstas sean garantes de satisfactorios resultados en el manejo de conflictos.

Las falencias que se presentan son tanto de forma como de fondo en su procesamiento al utilizar las competencias de convivencia; de igual forma su inclusión en la institución educativa no es adecuada.

La literatura encontrada establece que las principales falencias en la mediación escolar obedecen a factores tales como su ausencia en el manual de convivencia; no existe un proceso estructurado para su aplicación; no hay seguimiento de los proyectos presentados, falta de apropiación por parte de la comunidad educativa, baja o nula orientación y preparación para pares mediadores y ausencia de perfiles definidos para tal rol.

En cumplimiento de la función de preservar la seguridad ciudadana y procurar la sana convivencia, la Institución Policial ha asumido desde sus directrices la necesidad de formar policías mediadores de conflicto para responder 
a los retos de del posconflicto y del quehacer policial.

Añadiendo el análisis de los datos obtenidos por las autoras en dos escuelas rurales en la cercanía del municipio del Zulia, se tiene argumentos en cuanto:

Relación existente entre los estudiantes

\begin{tabular}{cccc}
\hline $\begin{array}{c}\text { Relación entre } \\
\text { estudiantes }\end{array}$ & Frecuencia & \% Relativo & \% Acumulado \\
\hline Excelente & 0 & $0 \%$ & $0 \%$ \\
Buena & 25 & $42 \%$ & $42 \%$ \\
Regular & 31 & $52 \%$ & $93 \%$ \\
Mala & 4 & $7 \%$ & $100 \%$ \\
\hline $\mathrm{S}$ & 60 & 1.00 & \\
\hline
\end{tabular}

Figura 1: Creación propia: información suministrada por encuesta realizada.

Lo más significativo es que de los encuestados ni un miembro percibe la relación entre ellos como Excelente, lo que da cabida a especular el ambiente escolar no es el mejor para ellos, continuando se destaca que la mitad de los alumnos más uno, asume que dicha relación es regular y el $42 \%$ de ellos la consideran como buena. Cerrando la lectura de datos, es claro que una fracción de $7 \%$ siente mal la relación que vive día a día con sus compañeros, esta podría ser un primer indicativo de alarma a posibles hechos de conflictos en las aulas de clase.

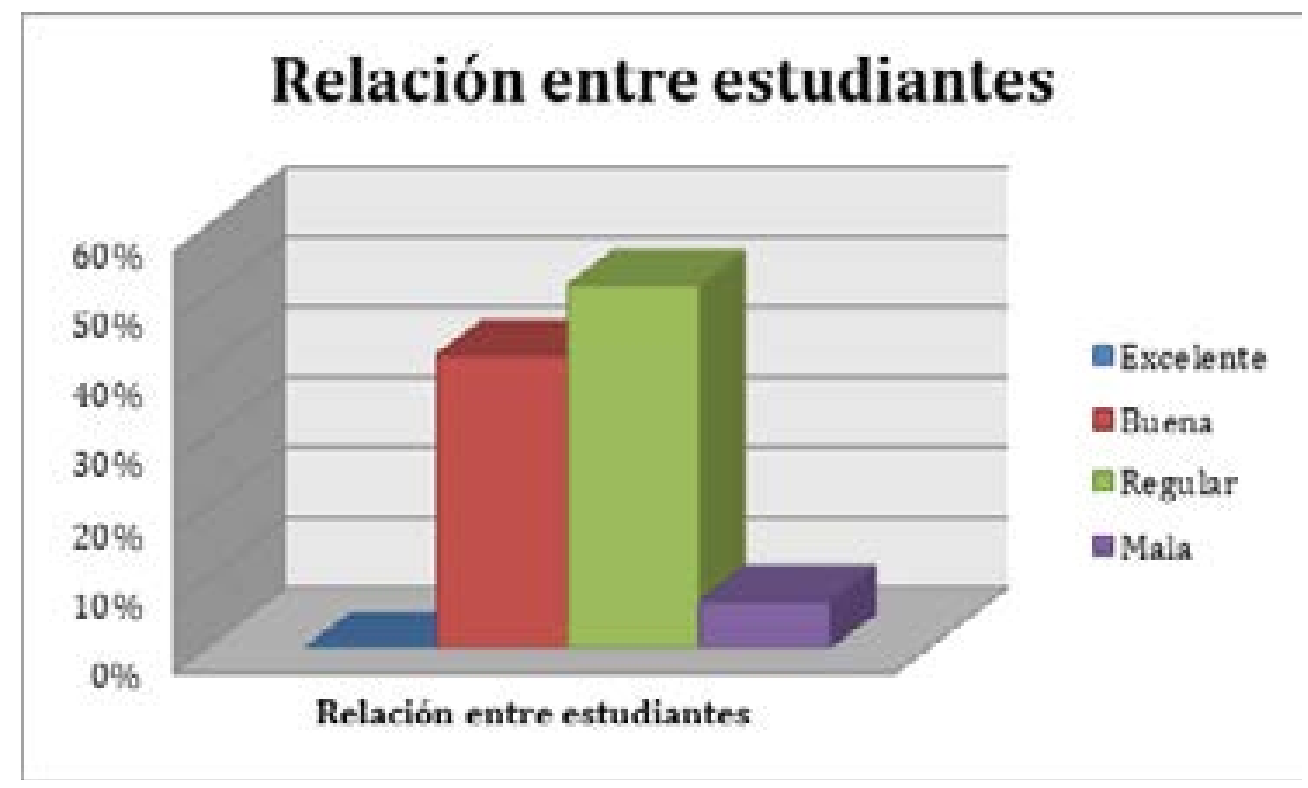

Figura 2: Creación propia: información suministrada por encuesta realizada. 
Modalidad de conflicto

\begin{tabular}{|c|c|c|c|c|}
\hline $\begin{array}{c}\text { Modalidad de } \\
\text { Conflicto }\end{array}$ & Siempre & $\begin{array}{c}\text { Casi } \\
\text { siempre }\end{array}$ & A veces & Nunca \\
Ofensas verbales & $55 \%$ & $15 \%$ & $30 \%$ & $0 \%$ \\
Agresiones Físicas & $18 \%$ & $27 \%$ & $55 \%$ & $0 \%$ \\
Uso de Armas & $0 \%$ & $0 \%$ & $3 \%$ & $97 \%$ \\
Usan otras personas & $10 \%$ & $40 \%$ & $48 \%$ & $2 \%$ \\
\hline
\end{tabular}

Figura 3: Creación propia: información suministrada por encuesta realizada.

Iniciando con las ofensas verbales, la mayoría $(55 \%)$ de los estudiantes encuestados consideran que Siempre tienen protagonismo las palabras hirientes en sus conflictos escolares, las agresiones físicas se presentan $A$ veces entre los alumnos implicados según el $55 \%$ de ellos, en cuanto al uso de armas el $97 \%$ de ellos creen que Nunca se han usado en sus disputas escolares mientras un $3 \%$ considera que $A$ veces se usan; así mismo involucrar otras personas en el conflicto y no precisamente como mediador, casi la mitad de menores creen que se da y el $40 \%$ afirma que casi siempre ocurre este accionar.

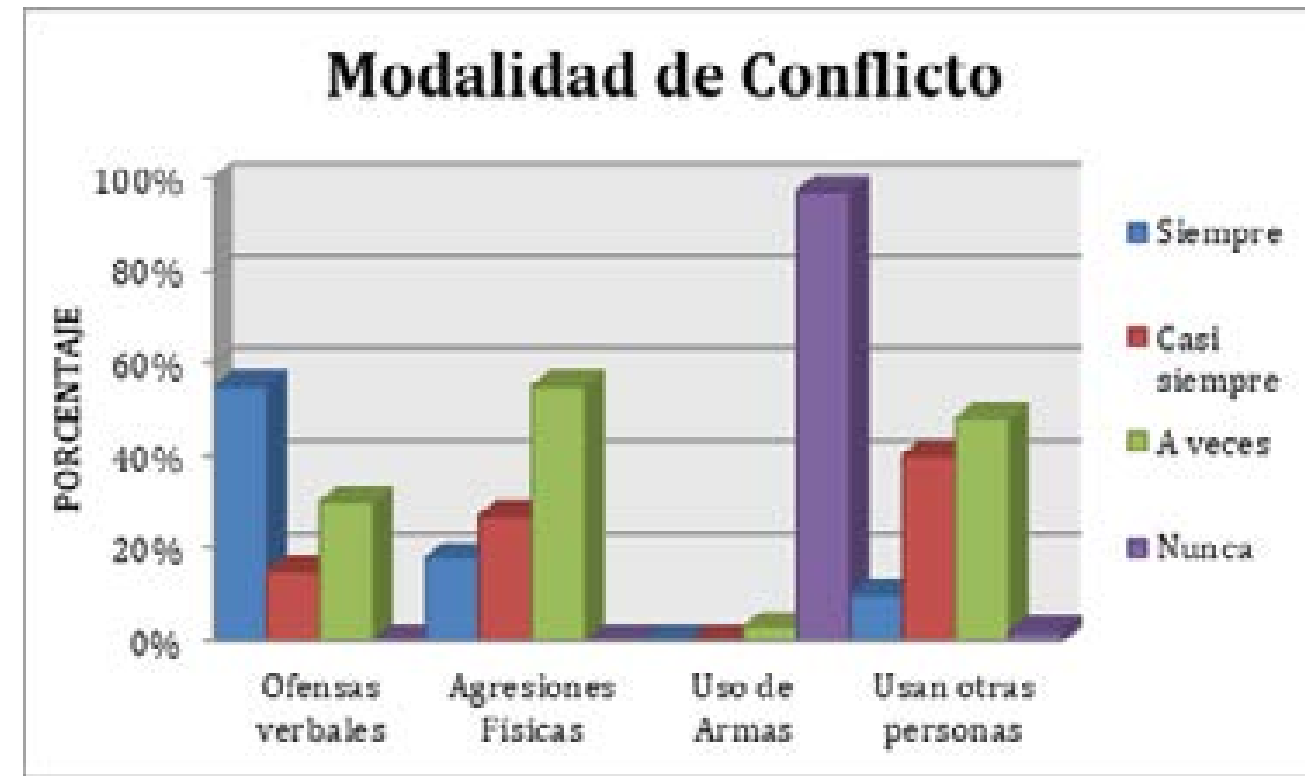

Figura 4: Creación propia: información suministrada por encuesta realizada.

\section{Motivos del conflicto}

\begin{tabular}{|c|c|c|c|c|}
\hline Motivos de Conflicto & Siempre & $\begin{array}{c}\text { Casi } \\
\text { siempre }\end{array}$ & A veces & Nunca \\
\hline Rechazo de los compañeros & $0 \%$ & $10 \%$ & $73 \%$ & $17 \%$ \\
\hline Discriminación & $0 \%$ & $7 \%$ & $75 \%$ & $18 \%$ \\
\hline Problemas de escuela & $0 \%$ & $70 \%$ & $30 \%$ & $0 \%$ \\
\hline Problemas familiares o externos & $2 \%$ & $8 \%$ & $88 \%$ & $2 \%$ \\
\hline
\end{tabular}

Figura 5: Creación propia: información suministrada por encuesta realizada. 
En esta categoría es observable como la tendencia es mayor a una respuesta a diferencia de las anteriores analizadas donde los datos eran más distribuidos.

El $73 \%$ de los encuestados concuerdan con que el motivo de los conflictos $A$ veces se da por rechazo de los compañeros y la segunda respuesta más optada es que este hecho No tiene nada que ver con el origen de pleitos entre ellos. Continuando así, el $75 \%$ considera que se genera por actos discriminatorios $A$ veces y el $18 \%$ piensa que No es un móvil; Es un dato muy concreto que ningún niño piense que los problemas de la escuela No tienen nada que ver, traduciéndose esto en que todos ellos piensan que los conflictos se generan por problemas de la escuela en cierta medida, el $70 \%$ dicen que Casi siempre y el $30 \%$ que A veces. En cuanto a que se den por problemas familiares, la mayoría $(88 \%)$ creen que $A$ veces es así, el $8 \%$ que casi siempre, No se elimina la opción que este tema no tenga nada que ver ni que siempre sea por este motivo las confrontaciones.

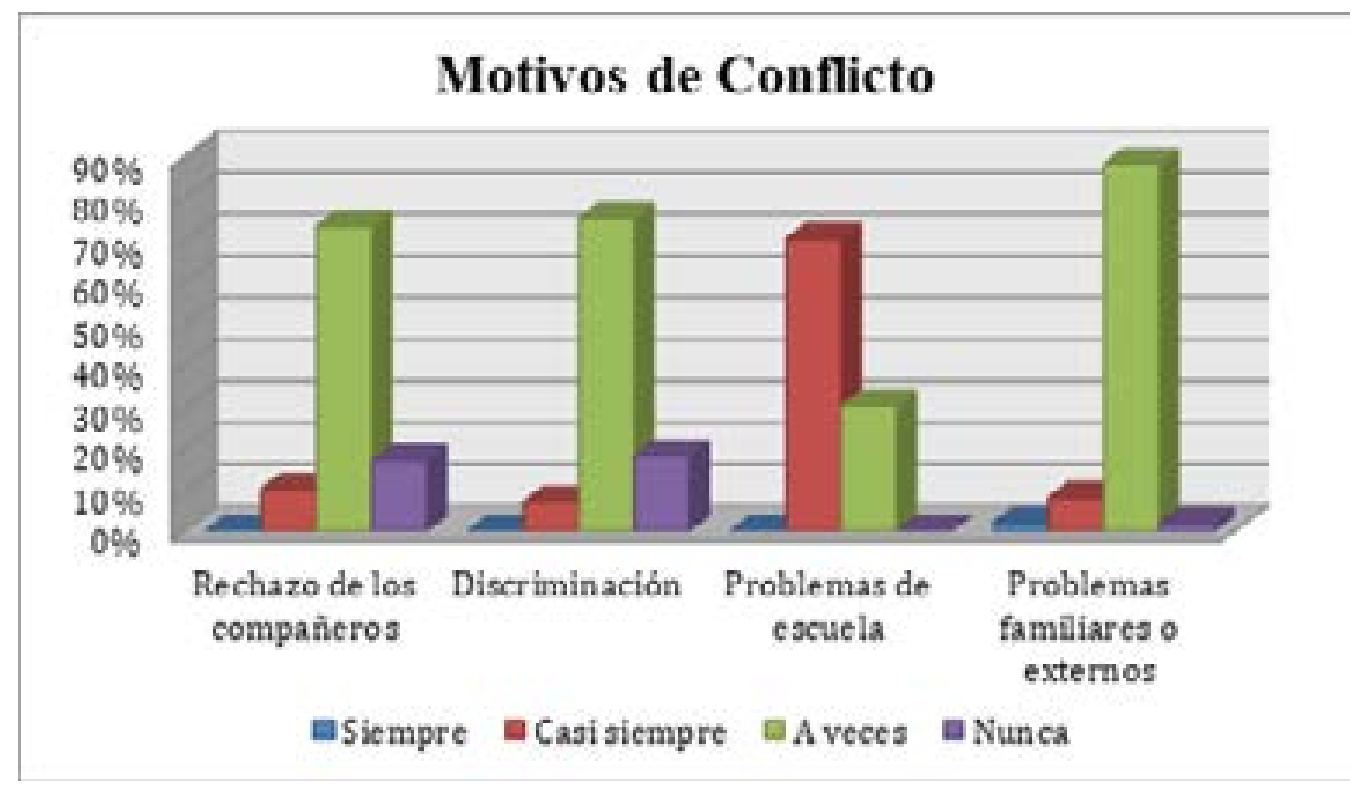

Figura 6: Creación propia: información suministrada por encuesta realizada.

\section{A quién acuden a solucionar el conflicto}

\begin{tabular}{c|c|c|c|c}
\hline $\begin{array}{c}\text { Acuden a solucionar } \\
\text { el conflicto a: }\end{array}$ & Siempre & $\begin{array}{c}\text { Casi } \\
\text { siempre }\end{array}$ & A veces & Nunca \\
Docente & $8 \%$ & $32 \%$ & $60 \%$ & $0 \%$ \\
Compañeros & $37 \%$ & $47 \%$ & $18 \%$ & $0 \%$ \\
Padres de familia & $0 \%$ & $3 \%$ & $75 \%$ & $22 \%$ \\
Particulares & $0 \%$ & $0 \%$ & $45 \%$ & $55 \%$ \\
Policía Nacional & $0 \%$ & $0 \%$ & $20 \%$ & $80 \%$ \\
\hline
\end{tabular}

Figura 7: Creación propia: información suministrada por encuesta realizada. 
A la hora de solucionar un conflicto el $60 \%$ de los estudiantes acuden $A$ veces al docente, solo el $8 \%$ acuden siempre a ellos y en todos los casos tienen en cuenta al profesor en mayor o menor proporción, tampoco descartan la opción de recurrir a sus compañeros para solucionar sus diferencias y la mayoría (47\%) lo hace casi siempre; Es destacable que hay alumnos que Nunca recurren a los padres de familia, a particulares o la policía siendo estos últimos los que mayormente Nunca recurren.

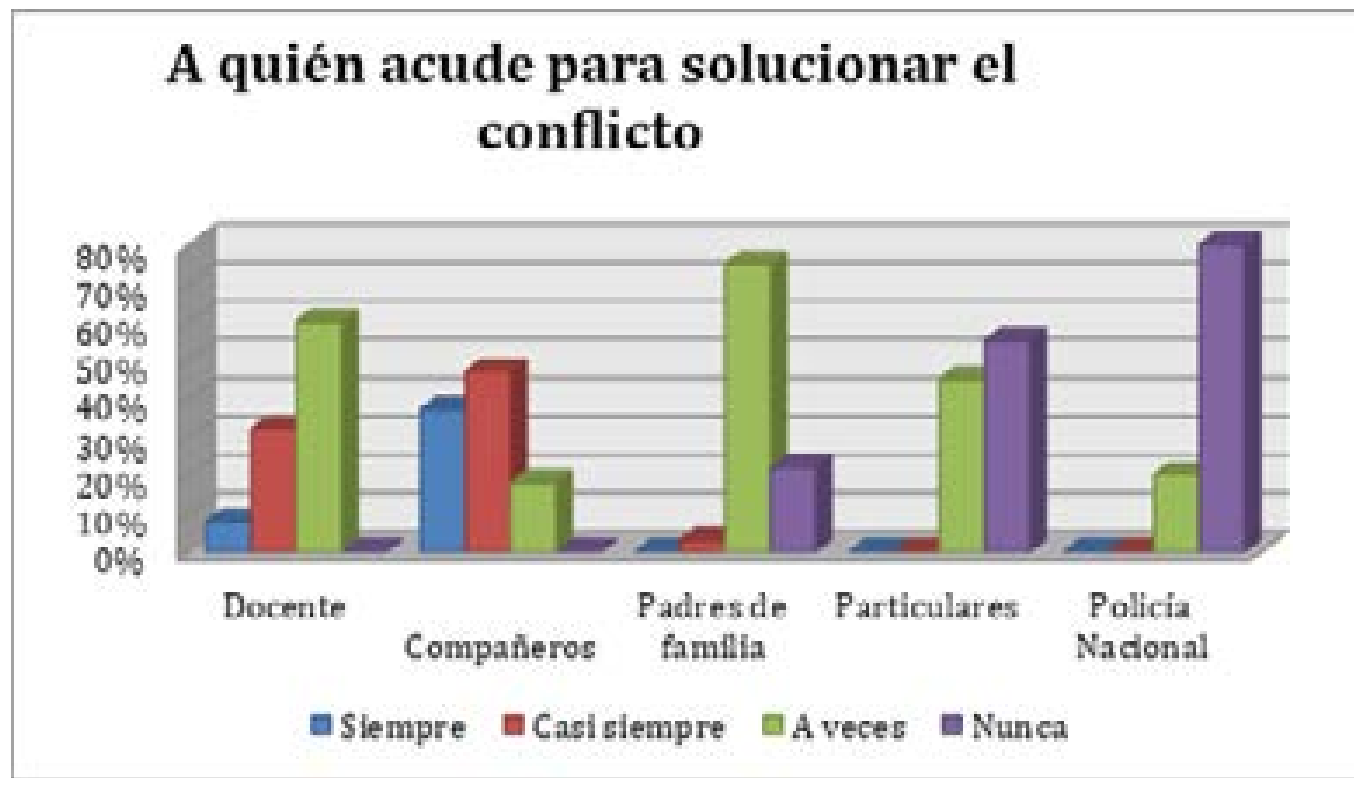

Figura 8: Creación propia: información suministrada por encuesta realizada.

Así mismo, el aporte personal que se le da a esta investigación y que tuvo acceso y acercamiento a la realidad, al aplicar entrevistas y encuestas a un grupo de estudiantes y maestros, que no representan significativamente el universo de estudio, pero que si permite esa visión particular del problema, se agrega a los las siguientes apreciaciones:

Los conflictos escolares afectan a gran parte de la población estudiantil.

Los móviles de los conflictos en la escuela son, principalmente los problemas escolares, seguido de los problemas familiares, la discriminación y el rechazo.

Generalmente las ofensas verbales son la mayor forma de violencia, seguida de las agresiones físicas, sin que se presente el uso de armas.

Se acude a los padres de familia, docente y compañeros para la solución del conflicto; muy escaso es el requerimiento a la policía, pero esto se debe a que No hay mayor presencia policial.

Se puede inferir la trascendencia en doble vía de los conflictos escolares, sociales y familiares Hay aceptabilidad por la mediación, pero no se aplican por falta de promoción.

Los lineamientos establecidos por el MEN buscan fomentar la mediación escolar

La falta de tiempo, formación y espacio impide su aplicación

Hay disponibilidad por parte de estudiantes y docentes para aceptar este tipo de programas

La Interacción escuela - policía es muy esporádica, existiendo lazos de respeto y colaboración 


\section{DISCUSIÓN}

Esta investigación no permitió describir en términos generales el estado actual de la mediación escolar en el sector rural, pero si se pudo logra un acercamiento bastante importante para poder entrar a hacer una propuesta proactiva que implique su utilización en el servicio de Policía como herramienta que potencialice el uso de la mediación Policial en las comunidades rurales.

En primer lugar, se debe establecer las fortalezas y limitaciones del estudio. Valga decir que la principal fortaleza es el interés y la importancia del tema, máxime si este se considera como una estrategia de institucional para abordar el posconflicto y desarrollar la misión policial de seguridad y convivencia; sin embargo, siendo un tema de tanta relevancia, vigencia y validez, debió afrontar como debilidad la poca literatura de estudios de caso y aplicación de la mediación escolar rural en Colombia. Se requieren de espacios y experiencias en las que actué el diálogo como agente mediador, los acuerdos fruto de las deliberaciones propias de los educandos y la concertación.

En términos generales se puede decir que:

La resolución de conflictos debe estar fundada en la dignidad humana, el respeto por la diferencia entre pares, la capacidad de perdón y reconciliación.

Se necesita reestructurar los Manuales de Convivencia donde se establezcan estrategias para resolver conflictos que se legitimen con la participación de la comunidad educativa.

La Mediación escolar puede ser utilizada como método alternativo para resolver los conflictos escolares, basándose en los principios de convivencia ciudadana basados en la paz y la democracia.
El principal objetivo de la estrategia de mediación escolar es la prevención y resolución de conflictos por medio del diálogo, el consenso y la concertación donde los actores de este proceso sean los pares estudiantiles

No se puede pensar en la aceptación de la mediación como alternativa para resolver conflictos cuando NO se ha educado en mediación. La cultura de la resolución de conflictos por medio de pares, sin recurrir a las vías jurídicas se debe fundamentar en la escuela.

Por el momento es imposible pensar en aportes de la mediación escolar a la mediación policial cuando la primera no existe sino teóricamente; por lo tanto, se debe invertir la propuesta para que desde la institucionalidad de la Policía Nacional se proyecte la mediación escolar rural $y$, a un futuro, esta sea el fundamento de la mediación policial rural.

\section{CONCLUSIÓN}

El estado actual de la mediación escolar en el sector rural es bastante precario, puesto que su aplicación se limita a esporádicos casos pilotos que no han sido replicados de manera masiva en beneficio de la misma comunidad educativa;

La utilización de la mediación escolar rural para potencializar el uso de la mediación Policial en las comunidades rurales, temporalmente, por sustracción de materia, no es posible.

El accionar de la Mediación escolar como mecanismo para la resolución de conflictos en la Educación Rural está limitado porque no existen herramientas, espacios y formación profesional direccionada a los estudiantes para que asuman su rol de mediador haciendo de la mediación una herramienta opcional, que depende del conocimiento de los educadores y si la desean o no aplicar en sus aulas. Al no estar estipulada oficialmente como medio de resolución de conflictos, actualmente es aplicada a criterio de 
la persona que presencie algún conflicto en el colegio.

La poca información y evidencias del empleo de la mediación escolar en el país, limita el acceso a datos reales de sus resultados al momento de aplicarla en instituciones y potenciarla en el cuerpo policial.

Otra clara conclusión obtenida a través de este trabajo investigativo es la comprobación de la existencia de una problemática presente en nuestras escuelas, como las agresiones, abusos y conflictos por diferencias de cualquier índole, que en una escala institucional representa un asunto más de pleitos entre alumnos o malos entendidos por falta de tolerancia, pero que observando con lupa desprenden diferentes realidades en las personas implicadas.

Los factores de la mediación escolar que aportan a la mediación policial son la disponibilidad al diálogo, la necesidad de resolución de conflicto y la integración escuela comunidad.

Se puede decir que a partir de las pocas experiencias positivas de mediación escolar y de la actitud y disponibilidad del niño estudiante rural hacia este medio de resolución de conflictos si es posible potencializar la mediación policial, puesto que la imagen de autoridad que se tiene del Policía le genera confianza al joven.

Por último, a partir de este análisis, es posible una propuesta generalizada para la educación rural de mediación escolar que permita el fortalecimiento de la Mediación Policial; sin embargo, se requiere un trabajo de campo para hacer esta articulación, lo cual, por la situación pandémica, no es posible ejecutar.

\section{PROPUESTA}

\section{FORMACIÓN DE MEDIADORES ESCOLARES EN LA ESCUELA RURAL}

\section{Objetivos}

\section{Objetivo General}

Desplegar acciones de acompañamiento en las escuelas rurales para fomentar la formación de mediadores escolares

\section{Objetivos específicos}

Diseñar material de formación para la articulación del trabajo policial y la conformación de mediadores escolares rurales

Construir lazos de confianza entre la Policía Rural y la comunidad educativa

Promover la formación y conformación de los mediadores escolares rurales.

\section{FASES}

\section{Fase De Preparación}

Partiendo de las directrices del MEN y lo establecido en la legislación Nacional, diseñar módulos didácticos de formación de mediadores escolares

\section{Fase De Acercamiento}

Visitar escuelas rurales y socializar con docentes y estudiantes la necesidad de formar mediadores escolares

\section{Fase De Acompañamiento}

Acompañar el proceso de formación y conformación de los comités de mediación escolar en las escuelas rurales

\section{RESULTADOS ESPERADOS}

La cultura de la mediación es la base fundamental para la sana convivencia, poder educar a los 
niños de las escuelas rurales en un proceso de mediación donde el diálogo y la confianza sea la base del encuentro social, permitirá que se construyan ciudadanos que acepten y acompañen el accionar de la mediación policial. Se potencializa esta tarea Institucional desde la escuela rural

\section{REFERENCIAS BIBLIOGRÁFICAS}

Acosta R. O. y Morales L. D., (2018). La Práctica Pedagógica del Acto Educativo como Escenario de Mediación para la Convivencia Escolar. San Andrés Islas. Universidad de la Costa, CUC. Maestría Educación. En http://repositorio.cuc. edu.co/handle/11323/3007

Acosta S. R. y Arboleda L., (2019). La educación en mediación escolar como escenario de formación ciudadana. Revista ESPACIOS. ISSN 0798 1015. Vol. 40 ( $N^{\circ}$ 21) Año 2019. Pág. 1. Recibido: 20/06/2018 • Aprobado: 20/05/2019 - Publicado 24/06/2019. https://www. revistaespacios.com/a19v40n21/ a19v40n21p01.pdf

Arboleda M. E. (2018). Estudiantes Mediadores del Conflicto Escolar: Un Caso de Escuela Nueva. Maestría en Estudios en Infancias. Universidad de Antioquia. Medellín. En http://bibliotecadigital.udea.edu. co/dspace/bitstream/10495/10043/1/ ArboledaMartinezEdilma_2018_ DiversidadCultural.pdf

Alzate S. R. (2010). Importancia de la educación en resolución de conflictos. Revista de Mediación. Año 3. №6. (pág. 7). Octubre 2010. https://imotiva.es/wp-content/ uploads/2013/08/Revista_Mediacion_6. pdf

Cabana G. M. (2017). De los Mecanismos Alternativos de Solución de Conflictos en Colombia: Acerca de su Alcance y Desarrollo para su Implementación en los Municipios de Post-Conflicto. Trabajo de grado para optar por el título de abogada en la Universidad Católica de Colombia. Bogotá. En: https://repository.ucatolica. edu.co/bitstream/10983/14606/1/ DE\%20LOS\%20MECANISMOS\%20 ALTERNATIVOS \% 20 DE $\% 20$ SOLUCION \% 20 DE \% 20 C O N F L I C T OS \% 20 E N \% 20 COLOMBIA\%20\%281\%29.pdf

Castro J. I. (2013). Propuesta Para La Implementación de la Mediación Escolar como Método Alternativo de Resolución de Conflictos para la Construcción de una Convivencia Pacífica en las Instituciones Educativas Públicas de la Ciudad de Pasto. Universidad de Nariño. Centro de Estudios e Investigaciones Latinoamericanas -CEILAT- Especialización en Gerencia Social. Pasto. En: http://sired.udenar. edu.co/2333/1/35.pdf

Céspedes P. N., Camacho. B., E., Nieves L. E. y Suárez C. M. (2018). Elementos de formación en mediación policial para la Policía Nacional de Colombia y sus aportes en la construcción de paz. Revista Espacios Vol. 39 (Número 53). Pág. 5. En: http://www.revistaespacios. com/cited2017/cited2017-05.pdf

Céspedes P. N., Pabón M. L., Tafur D. D., Palomino L. N., Cervantes E. L. y Fajardo P. E. (2020). Fortalecimiento de las habilidades psicosociales para mejorar el servicio de policía y aumentar la confianza social. bol.redipe [Internet]. 1 de mayo de 2020 (5):88-112. Disponible en: https://revista.redipe.org/ index.php/1/article/view/977 
Congreso de la República de Colombia (2013, marzo 15). Ley 1620 de 2013. Diario Oficial No. 48.733 de 15 de marzo de 2013. En https://www.icbf.gov.co/cargues/avance/docs/ley_1620_2013.htm

Fajardo, E. y Parada, J. A. (2018) La formación ciudadana como factor indispensable para el ejercicio democrático y el cultivo de individuos autónomos y responsables. Revista Signos -Lajeado, 39 (2) Disponible en: http://univates.br/revistas/index.php/signos/article/view/1942

Fajardo, P. E. (2018) Equidad y calidad educativa en América Latina: Responsabilidades, logros, desafío e inclusión. Revista CEDOTIC de la facultad de ciencias de la educación. 3 (1). http:// investigaciones.uniatlantico.edu.co/revistas/index.php/CEDOTIC/article/view/1953

Fernández de la F. J. y Galán S. J. (2010). Caso de mediación escolar. Formación de mediadores escolares: un proyecto en expansión. Revista de Mediación. Año 3. № 6. (pág. 50). Octubre 2010. https://imotiva.es/wp-content/uploads/2013/08/Revista_Mediacion_6.pdf

Gallego C. A., Méndez P., L. (2018) Mediación del conflicto escolar: una estrategia de intervención para la convivencia escolar. Maestría en educación-Modalidad Virtual Universidad de la Costa CUC San Andrés islas, Colombia. 2018. https://repositorio.cuc.edu.co/bitstream/ handle/11323/3016/39351758-32780288. pdf?sequence=1\&isAllowed=y

González B. M. (2016). El verdadero fin del conflicto armado: Jóvenes vulnerables, educación rural y construcción de la paz en Colombia. Un informe del Centro Noruego para la Resolución de Conflictos. En https://www.nrc.no/globalassets/pdf/reports/noref_report_nrc_educacion_ colombia_2016.pdf

Instituto para la economía social (IPES, 2017) violencia juvenil y acoso escolar en el contexto de la economía informal - Foro violencia juvenil y educación para convivencia la paz. En

http://www.ipes.gov.co/images/informes/Estudios_e_investigaciones/Violencia_juvenil_y_acoso_ escolar_en_el_contexto_de_la_economia_informal.pdf

lungman S., (1996). La mediación Escolar. Lugar Editorial. Buenos Aires, 1996. En http://www.terras. edu.ar/biblioteca/16/16TUT_lungman_Unidad_3.pdf

López. V. (2016) Convivencia Escolar. Educación y Desarrollo Post-2015. Oficina de Santiago Oficina Regional de Educación PARAAMERICA Latina UNESCO. http://www.unesco.org/new/fileadmin/ MULTIMEDIA/FIELD/Santiago/pdf/APUNTE04-ESP.pdf

Luna G. M., (2018) La Mediación Escolar como Estrategia para la Convivencia en la Escuela. Trabajo de grado presentado como requisito parcial para optar al título de Magíster en Educación. Pontificia Universidad Javeriana. Cali. En http://vitela.javerianacali.edu.co/bitstream/handle/11522/10776/ Mediacion_escolar_estrategia.pdf?sequence=1\&isAllowed=y

Mendoza G. B., Cervantes H. A. y Pedroza C.F. (2016). Acoso escolar: diferencias en contextos educativos rural y urbano, en alumnado adolescente. Investigación y Ciencia de la Universidad Autónoma de Aguascalientes. Número 67: 62-70, enero-abril2016. En: https://www.redalyc.org/ jatsRepo/674/67446178009/html/index.html 
Ministerio de Educación de la República Dominicana. Dirección de Orientación y Psicología (2016). La mediación como herramienta de resolución de conflictos en el sistema educativo dominicano. Manual de entrenamiento para facilitadores. Santo Domingo, República Dominicana. https://www.unicef.org/ republicadominicana/Medicacion_ Resolucion_Conflictos_WEB.pdf

Morales, M. y López, V. (2019). Políticas de convivencia escolar en América Latina: Cuatro perspectivas de comprensión y acción. Archivos Analíticos de Políticas Educativas, 27(5). http://dx.doi. org/10.14507/epaa.27.3800

Mujica J., Moncada H. Díaz M., Camacho B., E. y Céspedes P., N. (2017). Fundamentos Jurídicos $\mathrm{Y}$ Procedimentales De La Mediación Policial En Colombia. Policía Nacional Dirección Nacional De Escuelas Vicerrectoría de Investigación Bogotá, 2017 http:// biblioteca.policia.edu.co:8080/ bitstream/handle/123456789/1077/ M E D I A C I O N P O L I C I A L . pdf?sequence $=1 \&$ isAllowed $=y$

Observatorio de Derechos Humanos y Paz de UNICIENCIA. (2019). Situación actual del bullying en Bucaramanga. "Una perspectiva que va más allá de una simple estadística, datos 2014 2018". Edición 3, Volumen 1 En: https:// observatorioddhhypaz.unicienciabga. edu.co/images/boletines/2019/BoletinNo3-Situacion-actual-del-bullying-enBucaramanga.pdf

Osete G.J. (2011). Educación Para La Ciudadanía y Mediación Escolar. Trabajo para optar por el título de Master en Gestión y Resolución de Conflictos: Mediación Universidad de Barcelona.
Octubre 2011. En: http://diposit.ub.edu/ dspace/bitstream/2445/22922/1/Tesis EpCyMediaci\%C3\%B3nEscolarDefiniti va.pdf

PatarroyoL.L.,(2018)PlanEspecialdeEducación Rural, desafíos y posibilidades. CINEP. Bogotá. EN: https://www.cinep.org. co/publicaciones/PDFS/20180893 CienDias93_6Educacion.pdf

Policía Nacional de Colombia - Dirección de Seguridad Ciudadana (2017). Mediación Policial en Colombia - Bases para su implementación. Bogotá. En: https://bibliotecadigital.ccb.org. co/bitstream/handle/11520/19663/ Mediaci\%c3\%b3n\%20policial\%20 $\% 28$ arch i vo $\% 20$ par a $\% 20$ we b \% $29 \% 2006-02-2018$. pdf?sequence $=1$ \&isAllowed $=y$

Rosa Pulido V. R., Martín S. G y Lucas M. B. (2010). El papel de la mediación entre la familia y la escuela como prevención de la violencia Revista de Mediación. Año 3. № 6. (pág. 22). Octubre 2010. https:// imotiva.es/wp-content/uploads/2013/08/ Revista_Mediacion_6.pdf

Pulido, R., Martín S., G. y Lucas M., B. (2013). Orígenes de los programas de mediación escolar: diferentes enfoques que influyen en esta práctica restaurativa. Anales De Psicología / Annals of Psychology, 29 (2), 385-392. https://doi.org/10.6018/ analesps.29.2.132601

Pulido R., Fajardo T., Pleguezuelos L. y De Gregorio R. (2010). La mediación escolar en la comunidad de Madrid: Análisis del impacto de la formación en el profesorado y alumnado en el IES "las Américas" de Parla. Revista de Mediación. Año 3. № 6. (Pág. 32). Octubre 2010. https:// revistademediacion.com/articulos/la- 
mediacion-escolar-en-la-comunidad-de-madrid-analisis-del-impacto-de-la-formacion-en-elprofesorado-y-alumnado-en-el-ies-las-americas-de-parla/

Ramírez S. G., Céspedes P. N. (2016). Rol mediador de la policía nacional de Colombia en el posconflicto: Un estudio del discurso de expertos con AED Diversitas: Perspectivas en Psicología, vol. 12, núm. 2, 2016, pp. 183-199. Universidad Santo Tomás. Bogotá, Colombia. En https://www. redalyc.org/articulo.oa?id=67946836002

Soler B. J. (2011). El Desarrollo de Competencias Ciudadanas en la Escuela- Módulo: "La mediación de conflictos entre pares y la formación de competencias ciudadanas en la escuela" Corporación Opción Legal - Bogotá. En: https://opcionlegal.org/sites/default/files/mediacion_de_conflictos. pdf

Steele G. (2018). Mediación policial. Un protocolo de prevención del delito y cultura de paz En. Revista Justicia, Barranquilla: Editorial Mejoras-Universidad Simón Bolívar, Vol. 24, No. 34, pp.471-506. En: http://revistas.unisimon.edu.co/index.php/justicia/article/view/3403/4118

Suárez D.D., Liz A., Parra M. C. (2015, enero-junio). Construyendo tejido social desde la Escuela Nueva en Colombia. El caso Chimbe. Rev. Cient. Gen. José María Córdova 13(15), 195-229. En: http:// www.scielo.org.co/pdf/recig/v13n15/v13n15a08.pdf 